\title{
Alterations of serine racemase expression determine proliferation and differentiation of neuroblastoma cells
}

He Zhang

Jinfang Lu

Huiping Shang

Juan Chen

Zhengxiu Lin

Yimei Liu

Xianwei Wang

Liping Song

Xue Jiang

Haiyan Jiang

Jiandong Shi

Dongsheng Yan

Shengzhou Wu ( $\nabla$ wszlab@wmu.edu.cn )

\section{Research Article}

Keywords: Serine racemase, Neuroblastoma, Nude mice, Proliferation, Differentiation

Posted Date: January 19th, 2022

DOI: https://doi.org/10.21203/rs.3.rs-1276348/v1

License: (c) (1) This work is licensed under a Creative Commons Attribution 4.0 International License. Read Full License 


\section{Abstract}

Genetic deletion of serine racemase(SR) causes development disability of neuronal dendrites whereas increased expression of SR is found in differentiated cells in culture. These observations suggest roles of SR in cell proliferation and differentiation. Very recently,we have characterized increased SR expression when a neuroblastoma cell line,N2A,undergoes differentiation. However,whether and how the expression levels of SR determine cell destiny remains unclear. We herein indicated that valproic acid(VPA) or alltrans retinoic acid induced N2A differentiation which was mitigated by knockdown of SR. Knockdown of SR increased N2A proliferation,promoted cell cycle entry,and modulated expression of cell cycle-related proteins in N2A cells. Tumor formation in nude mice was used to further examine the effect of SR expression on cell destiny. N2A cells stably expressing scramble shRNA(Srrtrt-N2A) or Srr shRNA (SrrkdN2A) were subcutaneously injected into nude mice,respectively. The tumors growing from Srrwt N2A,significantly mitigated by intraperitoneal injection of VPA, were smaller than the tumors growing from

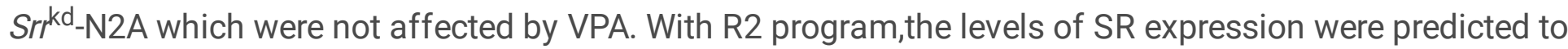
be positively correlated with survival probability in neuroblastoma patients. This study unveils that alteration of SR modulated proliferation and differentiation of neuroblastoma cells and the mechanism. The results further suggest that induction of SR expression is a novel strategy to treat neuroblastoma.

\section{Introduction}

Serine racemase(SR) is a pyridoxal-5'-phosphate(PLP)-dependent enzyme which catalyzes racemization to preferentially produce $\mathrm{D}$-serine and $\mathrm{a}, \beta$-elimination reaction to generate pyruvate and ammonia(1). Dserine is an endogenous coagonist of $\mathrm{N}$-methyl-D-aspartate receptor(NMDA-R), fine-tuning its activity $(2$, 3). Elaborate maintenance of $D$-serine participates in essential physiology including synaptic plasticity,neurotransmission, and cell migration(4-6). Thus,alterations of SR expression and D-serine levels are involved in neuropsychiatric disorders.

Reduced levels of SR and D-serine leading to hypoactivation of NMDA-R activity has been linked with schizophrenia $(7,8)$. A few studies suggest that genetic deletion of SR causes development delay of dendrites and instability of synapse which underlie the pathology of schizophrenia. For example,deletion of SR in mice produces less elaborate dendrite arborization and decreased spine density of pyramidal neurons in primary somatosensory cortex and of the neurons in the hippocampal formation $(9,10)$. These observations suggest that deficiency of SR postpones the development of newborn neurons. Conversely,SR is increased in differentiated cells or tissues. For example,SR is increased in confluent keratinocyte cultures compared with growing phase of cultures(11). P19 cells,a line of pluripotent embryonal carcinoma,express SR when induced differentiation into neurons or glia by all-trans retinoic acid;this differentiation is not overcome by inhibiting synthesis of D-serine(12). Emerging study indicates that $\mathrm{SR}$ is increased in colorectal adenoma and more significantly in advanced stage(13). Thus, alteration of SR expression may mediate cell proliferation and differentiation. 
Neuroblastoma is considered to derive from undifferentiated neural crest cells(14). Originating from sympathoadrenal nervous system,neuroblastoma is an extracranial tumor which accounts for more than $7 \%$ of malignancies in pediatric patients and $\sim 15 \%$ of all pediatric deaths due to cancers(15). Although overall survival has improved, around $36 \%$ of patients due to the characteristics of metastasis and undifferentiation-related malignancy remain difficult to be cured(16). For these portions of pediatric patients,overall survival rates remain below $40 \%$ in spite of multimodal therapies including radiotherapy,myeloablative chemotherapy,immunotherapy,and aggressive surgery(17). The detailed molecular events driving neuroblastoma are unclear but the genes regulating proliferation and differentiation of neural crest stem cells are thought to underlie the initiation and progression of neuroblastoma(18). For example,mutation of the anaplastic lymphoma kinase(ALK) gene has been found in $50 \%$ familiar and $5-15 \%$ of sporadic cases of neuroblastoma(19-21). Amplification of MYCN-which has homology to but distinct with $v$-myc $(22,23)$ - is found in $\sim 25 \%$ cases and correlates with high-risk neuroblastoma(14). Together with DNA diploidy and 11q alterations, amplification of MYCN is used to indicate poor prognosis(14). Either ALK mutation or amplification of MYCN is involved in the occurrence of neuroblastoma because these mutations cause uncontrolled cell proliferation and inability to differentiation $(24,25)$. Thus,the investigations of how neuronal fate is determined and of what factors contribute to the proliferation and differentiation of neuroblastoma cells are warranted regarding the challenges with neuroblastoma therapy.

Very recently,we found that valproic acid(VPA) induced SR expression in the context of differentiated condition but failed to increase SR in undifferentiated milieu(26). Thus, we aim to explore whether and how SR modulates differentiation of N2A cells. With in vitro cultures,we found that SR mediated the differentiation effect of VPA on N2A cells whereas knockdown of SR promoted its proliferation. The effects resulted from alteration of the expression of cell cycle-related proteins. With nude mice to develop neuroblastoma in vivo,stable knockdown of SR increased tumor proliferation and VPA mitigated the proliferation of tumors only under the context of normal SR expression. This study highlights a novel role of SR in differentiation of neuroblastoma cells and further suggests that intervention by inducing SR expression may be an invaluable therapy against neuroblastoma.

\section{Materials And Methods}

The following materials were used in this study:PrimeSTAR ${ }^{\circledR}$ HS DNA polymerase (cat\# R010A),pMD18-T vector(cat\# 6011),PrimeScript ${ }^{\mathrm{TM}}$ RT reagent kit with gDNA eraser,Kpnl,and Xbal(Takara Bio,Dalian,China). Trizol reagent,lipofectamine 2000,pcDNA3.1 (cat\#V79520)(Invitrogen,Carlsbad,CA,USA). SYBR ${ }^{\circledR}$ Green PCR master mixture(Life Technology,NY,USA). DMEM(cat\# 12430-047),0.05\% trypsin(cat\# 25300054), and Opti-MEM media(cat\# 31985-070)(Gibco,Shanghai,China). FBS(cat\# 04-001-1ACS)(Biological Industries,Israel). Penicillin-Streptomycin(cat\# C0222), phenylmethanesulfonyl fluoride(PMSF,cat\# ST505), protease inhibitor cocktail(cat\# P1010), and BCA protein assay kit(cat\# P0012)(Beyotime Biotechnology,Shanghai, China. Neuro-2a(N2A)(cat\# CCL-131,RRID:CVCL_0470,ATCC,Manassas,VA,USA). Valproic acid(cat\#HY-10585),DMSO, and D-serine(cat\#HY-100808)(MedChemExpress, Shanghai,China). 
The antibodies used in this study included:mouse monoclonal anti-SR(cat\# 612052,RRID:AB_399439) (BD,Biosciences,San Jose,CA,USA);rabbit monoclonal anti-pH3(phospho-histone H3) (cat\# 53348T,RRID:AB_2799431),rabbit monoclonal anti-CyclinD1 (cat\# 55506T ), mouse monoclonal antiP27(cat\#3698T, RRID:AB_2077832), and rabbit monoclonal anti-phospho-Rb(Ser807/811) (ca \#8516T,RRID:AB_11178658)(Cell Signaling Technology,Beverly,MA,USA). Mouse monoclonal antiP21 (cat\# sc-271610,RRID:AB_10647231) and mouse monoclonal anti-glyceraldehyde-3-phosphate dehydrogenase(GAPDH)(cat\# sc-47724,RRID: AB_627678)(Santa Cruz Biotechnology,Santa Cruz,CA,USA). Mouse monoclonal anti-neuronal class III $\beta$-tubulin(Tuj1)(cat\# AT809)(Beyotime Biotechnology,Shanghai,China) Rabbit monoclonal anti-Ki67(cat\# ab16667,RRID:AB_302459,Abcam,Cambridge,MA, USA). Peroxidase-conjugated goat anti-mouse $\lg \mathrm{G}(\mathrm{H}+\mathrm{L})$ antibody (cat\# ZB-2305, RRID:AB_2747415) and horseradish-labeled goat anti-rabbit IgG $(\mathrm{H}+\mathrm{L})$ antibody (cat\# ZB-2301,RRID: AB_2747412)(ZSGB-Bio,Beijing,China). Alexa fluor ${ }^{\circledR} 488$-conjugated secondary antibody(RRID:AB_143160,Thermo Fisher Scientific Inc,USA). Alexa fluor ${ }^{\circledR}$ 594-conjugated secondary antibodies (RRID:AB_141672, Thermo Fisher Scientific Inc,USA). Mounting medium containing DAPI(RRID:AB_2336790,Vector Laboratories, Inc,CA, USA).

\section{Study approval}

The procedures to manipulate animals and to reduce animal discomfort were approved by the Institutional Review Board of Wenzhou Medical University(approval number\# wydw2020-0297).

\section{Cell culture}

Neuro-2a(N2A) cells were cultured in Dulbecco's Modified Eagle's Medium(DMEM) supplemented with $10 \%$ fetal bovine serum(FBS). Under differentiated condition,the media were switched into DMEM plus $1 \%$ FBS containing $1 \mathrm{mM}$ VPA. The cultures were maintained in a humidified $5 \% \mathrm{CO} 2$ incubator at $37^{\circ} \mathrm{C}$.

\section{Real-time quantitative reverse-transcription PCR}

N2A cells were cultured in 6-well plates at the density of 400,000 cell/well,in DMEM plus $10 \%$ FBS. After 24 hours, the culture media were switched to DMEM plus 1\% FBS containing $1 \mathrm{mM}$ VPA for inducing differentiation. At different timepoints subject to treatment,the cells were used for RNA extraction with Trizol reagent. Reverse transcription reaction was conducted to synthesize CDNA by use of a PrimeScript ${ }^{T M}$ RT reagent kit with gDNA eraser(Takara Bio). Twenty nanograms of cDNA was used as a template to amplify Srr and actin mRNA. The primers were used in qRT-PCR to amplify Srr and actin: $m$ Srr,forward primer, 5'-ACCCCAGTGCTAACAAGCTC-3', reverse primer,5'-ACTACGG CTTTGGGCTTCTC3';mß-actin,forward,5'-GAGGA GATTACTGCTCTGGCTCCTA-3',reverse,5'-TCATCGTACTCCTGCTTGCTGAT- 
3'. Similarly,the Power SYBR ${ }^{\circledR}$ Green PCR master mixture(Life Technology,NY,USA) was used as the reaction dye for the qRT-PCR reaction and all PCR reactions were conducted in a 96-well ABI plate format in ABI7500 (Applied Biosystems,USA).

\section{Western blot}

N2A cells were harvested and homogenized in Super RIPA buffer. Proteins were resolved on $12 \%$ SDSPAGE gels and transferred to nitrocellulose membranes. After sequential incubation with primary and secondary antibody,the membranes were developed with chemiluminescence system kit(ThermoFisher). Images of immunoblots were obtained with FlourChem E Systems(Proteinsimple,Santa Clara,MA,USA) and the optic densities of the immunoblots were quantified using Image J software(National Institutes of Health,Bethesda,MD,USA).

\section{Construction of SR-expressing plasmid}

Trizol reagents were used to extract RNA from N2A cell. With the extracted RNAs as a template,cDNA was synthesized with reverse transcription reaction kit(PrimeScript ${ }^{T M}$ RT reagent kit with gDNA eraser). By use of an enzyme mixture of an Ex Taq polymerase ${ }^{\circledR}$ (cat\# RR001A,Takara Bio) and a high-fidelity Taq polymerase (PrimeSTAR ${ }^{\circledR}$ HS DNA polymerase,Takara Bio) at the ratio of 1:1, PCR reaction was used to amplify Srr cDNA product with the forward primer,5'-ATGTGTGCTCAGTACT GCATCT-3', and the reverse primer,5'-CTAAACAGAAACCGTCTG GTAAGGAG-3'. The PCR products were analyzed with DNA electrophoresis and $\sim 1 \mathrm{kbp}$ DNA fragment was purified from agarose gel. With the purified product as a template,PCR reaction was used to synthesize product incorporating desired restriction sites and the Kozak sequence to enhance translation. The forward primer was 5'-AAGATCTCGAG GCCACCATGTGTG CTCAGTACTGCATCT-3', with Bglll restriction site and the Kozak consensus sequence underlined,respectively. The reverse primer was 5'-CAGAAAC CGTCTGGTAAGGAGTACCCATACGACGTCCCAGACTACGCTTAACTGCAGTCTA GA-3', with Pstl and Xbal restriction site underlined,respectively. After PCR reaction,the product was ligated to pMD18-T vector. After screening targeted clone with sequencing result, the bacterial clone was amplified and used to extract plasmid. The plasmid was restricted by sequential restriction of $\mathrm{Kpnl}$ and $\mathrm{Xbal}$ and ligated to similarly restricted pcDNA3.1. The ligated product was transformed into DH5a E.coli bacteria and the plasmid was extracted as a SR-expressing plasmid.

\section{Establishment of a SR-knockdown N2A cell line}

Initially,three plasmids expressing Srr shRNA were transiently transfected into N2A cells and SrrmRNA and SR protein levels were examined so as to screen knockdown efficacy. The plasmids screened 
included:sh336,GCTCAGTACTGCATCTCCTTT;

sh445,GGCGCAATCTCTTCTTCAAAT; sh597,GCTCTCACCTATGCTGCTAAA. The expression of each shRNA was driven by a U6 snRNA promoter in pGPU6/GFP/Neo (GenePharma,Shanghai). Interference plasmid sh445 reached maximal effect. Stable transfection of these GFP-containing plasmids(sh445) was used for generating SR-knockdown cell line. N2A cells were cultured in 6-well plates at the density of 400,000 cell/well,in DMEM plus 10\% FBS, until 60-70\% confluency. The culture media were switched into DMEM and transfected with pGPU6/GFP/Neo(GenePharma, Shanghai),expressing Srr shRNA(sh445,GGCGCAATCTCTTCTTCAAAT) or scramble RNA(NC,TTCTCCGAACGTGTCACGT) at $2 \mu \mathrm{g} /$ well. After four hours, the media were switched to DMEM plus $10 \%$ FBS supplemented with penicillin(100 unit/mL) and streptomycin $(100 \mu \mathrm{g} / \mathrm{mL})(P S)$ for another $24 \mathrm{~h}$. The transfected N2A cells were gently trypsinized,suspended,and selected with fluorescence-activated cell sorting (FACS), basing on GFP fluorescence. The selected N2A cells by FACS were cultured in DMEM plus $10 \%$ FBS supplemented with PS and G418(300 $\mu \mathrm{g} / \mathrm{mL})$ for three days. G418 was added to the culture to exclude N2A cells dislodging the transfected plasmids. The selection by addition of G418 and FACS were repeated at least five times to obtain high-purified SR-knockdown N2A cells.

\section{Neurite outgrowth assay}

For determination of the effect of VPA on neuronal differentiation,the neurons containing the neurite length more than two-fold neuronal soma diameter were considered as differentiated neurons and were counted and quantified(LEICA DMi8 Fluorescence Microscope). The measurement of neurite length was conducted in triplicate culture preparations and the values were averaged from between 150-200 cells in either group.

\section{Cell cycle analysis by fluorescence-activated cell sorting(FACS)}

N2A cells were cultured in 6-well plates at the density of 400,000 cells/well,in DMEM plus $10 \%$ FBS. After $24 \mathrm{~h}$,the culture media were switched into DMEM plus 1\% FBS and the cells were subject to vehicle or VPA treatment for $48 \mathrm{~h}$. After treatment,the cells were subject to gentle trypsinization and subsequent centrifugation. The supernatants were discarded and the precipitates were washed with PBS. With addition of ice-cold $70 \%$ ethanol,the cells were dispersed evenly for storage at $-20{ }^{\circ} \mathrm{C}$ until use. Before cell cycle analysis,the cells were washed and subject to propidium(PI) staining. With a cell cycle and apoptosis analysis kit(C1052,Beyotime Biotechnology),cell cycle was analyzed with BD FACSCalibur basing on PI staining intensity(BD Biosciences,San Jose,CA,USA).

\section{5-ethynyl-2'-deoxyuridine labeling}


5-ethynyl-2'-deoxyuridine(EdU) labeling was used for monitoring N2A proliferation. N2A cells were cultured on glass slides sitting in 12-well plates and treated by VPA $(1 \mathrm{mM})$ in DMEM plus $1 \% \mathrm{FBS}$ for 48 hours. EdU was added at a final concentration, $10 \mu \mathrm{M}$,for 2 hours. N2A cells were fixed in $4 \%$ paraformaldehyde at room temperature for 10 minutes,then washed with PBS three times. After wash,the neurons were blocked with $3 \%$ bovine serum albumin and permeabilized with $0.2 \%$ Triton-X100 at room temperature for 20 minutes. After wash,the neurons were incubated with developing solution(Click-i $\mathrm{T}^{\mathrm{TM}}$ EdU imaging kit) at room temperature for 30 minutes in the dark. The cells were coverslipped,and images were captured with a fluorescence microscope(LEICA DMi8 Fluorescence Microscope).

\section{Establishment of neuroblastoma model with nude mice}

Nude mice were purchased from Charles River Laboratories (Beijing) and fed in a standard pathogen-free animal facility for one week before experiment at the age of six weeks. The modified N2A cells as described above were gently digested by trypsin to single cell suspension and washed. The cells were made into $10^{7}$ cells $/ \mathrm{mL}$ cell suspension. By route of subcutaneous injection, $0.1 \mathrm{~mL}$ cell suspension was bilaterally injected into nude mice at the junction of hindlimb and abdomen. After 3.5 weeks,the mice developing approximately equal sizes of tumors were evenly assigned to groups either subject to intraperitoneal injection of vehicle or VPA $(250 \mathrm{mg} / \mathrm{kg})$. After two weeks, the mice were euthanized and tumors were immediately excised,using for evaluating the weights and sizes. The isolated tissues from tumor were also used for qRT-PCR and immunofluorescence.

\section{Utilization of R2 program}

The program of R2:Genomics Analysis and Visualization Platform(http://r2.amc.nl) with Kaplan scanning was used to predict the relationship between SR expression and the prognosis of neuroblastoma patients. Neuroblastoma Oberthuer(ArrayExpress:E-TABM-38),Neuroblastoma Versteeg(GEO:GSE16476 88/122), and Neuroblastoma SEQC(GEO:GSE62564),publicly available datasets,were used for the analysis. In brief,R2 program calculated the optimal cutoff expression for Srr by dividing the patients in a good and bad prognosis cohort. According to the expression of Srr,samples within a dataset were sorted and divided into two groups,high and low level of expression groups,on the basis of a cutoff expression value. All cutoff expression levels and their resulting groups were analyzed for survival. The cutoff level was reported and used to generate Kaplan-Meier graphs.

\section{Statistics}

All data were presented as means \pm SEM unless stated. Data were examined with Shapiro-Wilk test for normality distribution. For parametric data, Student's $t$-test was used to compare the differences between two groups. In experiments with more than two groups,the data were subject to one-way ANOVA,followed 
by Tukey's post-hoc test. When $p<0.05$,differences were regarded as significance. Survival rates were estimated by the Kaplan-Meier method,and the log-rank test was used to assess survival difference.

\section{Results}

\section{Elevation of SR expression was coupled with neuronal differentiation}

In previous study,we have indicated that VPA increases SR expression in DMEM plus $1 \%$ FBS but not in DMEM plus $10 \%$ FBS compared with sham treatment(26). With staining by use of a neuronal marker, $\beta I I-$ tubulin, differentiated neurons were identified by growing neurites longer than two-fold neuronal soma(Figure.1A). In DMEM plus 1\% FBS,VPA treatment $(1 \mathrm{mM})$ induced N2A differentiation when the treatments were applied between 24,48,72,and 96 hours,respectively(Figure.1A) whereas in DMEM plus $10 \%$ FBS, neurites did not grow. The percentages of cells undergoing differentiation in DMEM plus $1 \%$ FBS were increased when extending the treatment of VPA. For example,VPA induced $13.98 \%(p<0.0001 \mathrm{vs}$. sham treatment $), 47 \%(\mathrm{p}<0.0001), 61.88 \%(\mathrm{p}<0.0001)$, and $67.10 \%(\mathrm{p}<0.0001)$ of $\mathrm{N} 2 \mathrm{~A}$ cells to differentiate at $24,48,72,96$ hours of treatments,respectively(Figure.1B). So far,we indicated VPA induced the differentiation of N2A cells but the function of SR expression involving in neuronal differentiation is unclear.

\section{Knockdown of SR reduced neuronal differentiation}

Thus,we next analyzed the effect of knocking down SR on neuronal differentiation. By using shRNA,the effects of interference on SrrmRNA and SR protein levels were tested after transient transfection of plasmids expressing SrrshRNAs,i.e.,sh336, sh445,and sh597,respectively. The plasmids knocked down SrrmRNA to $44.8 \%(p=0.002), 36.9 \%(p=0.006)$, and $40.9 \%(p=0.006)$ and SR protein levels to $48.68 \%$ $(p=0.001), 43.98 \%(p=0.001)$, and $64.97 \%(p=0.007)$ of those from transfection of plasmid expressing scrambled shRNA(Supplemental Figures.1A-1C). Comparing the knockdown effects caused by the three plasmids,the plasmid expressing SrrshRNA (sh445) achieved maximal knockdown effect on Srr mRNA(63.1\%) and SR protein(56.02\%)(Supplemental Figures.1A-1C). Therefore,transfection of the plasmid expressing sh445 and subsequent application of G418 were used to generate stable SRknockdown cell line,namely,Srkd_N2A whereas the cells stably expressing scrambled shRNA were used as a control cell line,i.e.Srr ${ }^{\mathrm{wt}}$-N2A(Supplemental Figures.1D-1F). With the stably-transfected cell lines,significantly lower percentage of $\mathrm{Sr}^{\mathrm{kd}}-\mathrm{N} 2 \mathrm{~A}$ cells differentiated under the induction of VPA at the same length of treatment, compared with $\mathrm{Sr}^{\mathrm{wt}}-\mathrm{N} 2 \mathrm{~A}(\mathrm{p}<0.0001$ for 24,72 , and 96 hours of treatments, respectively; $\mathrm{p}=0.01$ for 48 hours of treatment)(Figures.2A and $2 \mathrm{~B}$ ). With extension of treatment, higher percentage of $\mathrm{Sr}^{\mathrm{wt}}{ }^{\mathrm{N}} \mathrm{N} 2 \mathrm{~A}$ cells underwent differentiation(Figures.2A and 2B), similar to the above findings(Figures.1A and 1B). Similarly,all-trans retinoic acid(RA) induced N2A differentiation and the percentages of the differentiation were increased when extending the treatment(Supplemental Figures.2A and 2B). Consistent with the differentiation effect,SR expression was gradually increased 
when the treatment time was extended(Supplemental Figures.2C-2E). Similar with VPA,RA induced higher percentages of differentiation in $\mathrm{Sr}^{\mathrm{wt}}-\mathrm{N} 2 \mathrm{~A}$ compared with those in $\mathrm{Sr}^{\mathrm{kd}}-\mathrm{N} 2 \mathrm{~A}$ cell(Supplemental Figures.2F and $2 \mathrm{G}$ ).

The differentiation defect in Srr ${ }^{\mathrm{kd}}-\mathrm{N} 2 \mathrm{~A}$ was rescued by SR overexpression (Figures.3A-3D). For example,overexpression of SR-expressing plasmid induced $45.99+/-2.85 \%$ of $\mathrm{Srr}^{\mathrm{kd}}-\mathrm{N} 2 \mathrm{~A}$ cells to differentiate whereas transfection of vehicle plasmid induced $10.03+/-1.58 \%$ of $\mathrm{Srr}^{\mathrm{kd}}-\mathrm{N} 2 \mathrm{~A}$ cells to differentiate under VPA induction ( $p<0.0001$ )(Figures.3A-3D). To our surprise, addition of D-serine $(20 \mu M)$

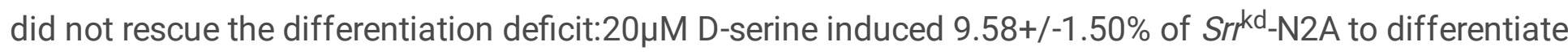
in comparison with $9.27+/-0.74 \%$ of cells to differentiate under sham treatment $(p=0.755)$ (Supplemental Figure.3). Notably,overexpression of SR in Srr ${ }^{\text {wt }}$-N2A did not promote differentiation(Figures.3E$3 \mathrm{H}$ ), i.e.,overexpression of SR-expressing plasmid induced $21.63+/-1.90 \%$ of $\mathrm{Sr}^{\mathrm{wt}}$-N2A cells to differentiate whereas transfection of vehicle plasmid induced $23.38+/-2.04 \%$ of $\mathrm{Sr}^{\mathrm{wt}}-\mathrm{N} 2 \mathrm{~A}$ cells to differentiate $(p=0.254)$ (Figures.3E-3H).

\section{Knockdown of SR promoted cell proliferation and cell cycle entry}

Reports indicate that the proteins promoting cell cycle exit may increase cell proliferation at lower level of expression. Thus,we explored whether knockdown of SR modulates cell proliferation. Srrd ${ }_{-N}{ }^{\mathrm{N}} 2 \mathrm{~A}$ and $\mathrm{Sr}^{\mathrm{wt}}$ N2A cells were labelled with a proliferation marker,EdU. As expected,higher percentage of $S r^{k d}{ }_{-N 2 A}$ cells compared with $S_{r r}{ }^{\mathrm{wt}}$-N2A were labeled with EdU staining under VPA treatment $(\mathrm{p}=0.005)$ (Figure.4B). We further subject the cells to cell cycle analysis. Higher percentages of $\mathrm{Srr}^{\mathrm{kd}}$-N2A cells $(20.08+/-1.15 \%)$ relative with $S_{r}{ }^{\text {wt }}{ }^{-N 2 A}$ cells $(12.91+/-0.91 \%)$ were retained in $S$ phase $\left({ }^{\star \star *} p<0.0001\right)$ (Figure.4A). Higher percentages of $\mathrm{Srr}^{\mathrm{kd}}{ }_{-\mathrm{N} 2 \mathrm{~A}}$ cells(30.8+/-2.59) relative with $\mathrm{Srr}^{\mathrm{Wt}}{ }^{\mathrm{W}} \mathrm{N} 2 \mathrm{~A}$ cells(23.92+/-4.34) were retained in $\mathrm{G} 2 / \mathrm{M}$ phase $\left(\mathrm{p}=0.01\right.$ ) (Figure.4A). Correspondingly,lower percentage of $\mathrm{Srr}{ }^{\mathrm{kd}}$-N2A cells stayed in G0/G1 phase $(49.12+/-2.7 \%)$ compared with Srr ${ }^{\mathrm{wt}}$-N2A cells in G0/G1 phase $(63.18+/-2.7 \%$; $<<0.0001)$ (Figure.4A). VPA treatment reduced the percentage of $S r r^{\mathrm{Nt}}{ }_{-} \mathrm{N} 2 \mathrm{~A}$ cell and $S r r^{\mathrm{kd}}-\mathrm{N} 2 \mathrm{~A}$ cells in $\mathrm{S}$ phase $(10.44+/-1.06 \%$ for

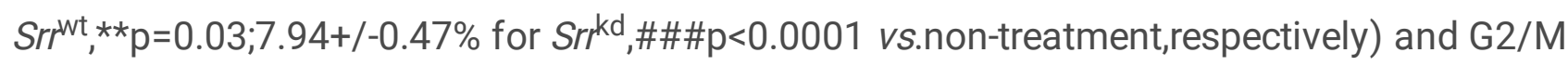
phase $\left(13.21+/-0.75 \%\right.$ for $S r r^{w t},{ }^{* * *} p<0.0001 ; 19.33+/-1.96 \%$ for $S r r^{k d}, \# \# \# p<0.0001$ vs.nontreatment,respectively). VPA treatment increased the percentages in G0/G1 phase compared with nontreatment,respectively $\left(76.35+/-1.67 \%\right.$ for $\mathrm{Sr}^{\mathrm{rt} t},{ }^{* \star \star} \mathrm{p}<0.0001 ; 72.74+/-2.2 \%$ for $\mathrm{Srr}^{\mathrm{kd}}, \# \# \# \mathrm{p}<0.0001$ vs.nontreatment,respectively)(Figure.4A). We further examined whether knockdown of SR modulated expression of cell-cycle related proteins. 


\section{Knockdown of SR modulated expression of cell-cycle related proteins}

We further analyzed the expression of cell cycle-related proteins. Consistent with EdU labeling,cell proliferation marker,pH3 and Ki67, were increased in VPA-treated $\mathrm{Sr}^{\mathrm{kd}}{ }_{-\mathrm{N}} \mathrm{NA}$ compared with VPA-treated Srrt ${ }^{\mathrm{Nt}}$-N2A( $\mathrm{p}=0.005$ for $\mathrm{pH} 3$ comparison; $\mathrm{p}=0.029$ for Ki67 comparison)(Figures.5E and 5G). CyclinD1 and $\mathrm{p}$-Rb,the proteins promoting G1/S transition, were increased in VPA-treated $\mathrm{Sr}^{\mathrm{kd}}$-N2A compared with those of VPA-treated $S r^{\mathrm{wt}}$-N2A( $\mathrm{p}=0.003$ for CyclinD1 comparison; $\mathrm{p}=0.0032$ for $\mathrm{p}$-Rb comparison) (Figures.5B and $5 F$ ). By contrast,P21 and P27,the proteins blocking G1/S transition, were decreased in VPA-treated $S r r^{k d}-N 2 A$ compared with VPA-treated $S r r^{\mathrm{wt}}$-N2A( $p<0.0001$ for P21 comparison; $\mathrm{p}=0.003$ for P27 comparison)(Figures.5C and 5D). In DMEM plus 10\%FBS,the proteins level of CyclinD1,P21,P27,pH3,pRB,Ki67 were not different between $\mathrm{Srr}^{\mathrm{kd}}$ and $\mathrm{Srr}^{\mathrm{NT}} \mathrm{N} 2 \mathrm{~A}$ cells,respectively(Supplemental Figure.4).

\section{SR expression was linked with efficacy against neuroblastoma}

To further test the effect of knockdown of SR on neuronal proliferation and differentiation,we subcutaneously injected $\mathrm{Sr}^{\mathrm{Nt}}$-N2A and $\mathrm{Sr}^{\mathrm{kd}}-\mathrm{N} 2 \mathrm{~A}$ into nude mice. After 3.5 weeks following transplantation,the mice were divided into groups subject to intraperitoneal injection of vehicle or of VPA. The tumors were isolated and analyzed on the $2^{\text {nd }}$ week after VPA or vehicle injection. The volumes of tumors developed from $\mathrm{Srr}^{\mathrm{wt}}-\mathrm{N} 2 \mathrm{~A}\left(\mathrm{NC}: 1.45+/-0.40 \mathrm{~cm}^{3}\right)$ were less than those from $\mathrm{Srr}^{\mathrm{kd}}$ $\mathrm{N} 2 \mathrm{~A}\left(\mathrm{sh} 445: 2.15+/-0.37 \mathrm{~cm}^{3}\right)(\mathrm{p}=0.02)$ (Figures.6A and 6D). Similarly,the weights of tumors developed from the former(NC:0.98+/-0.1g) were less than those from the latter(sh445:1.24+/-0.2g) $(p=0.03)$ (Figures.6B and 6D). Compared with vehicle,VPA injection significantly reduced the tumor sizes from Srr ${ }^{\mathrm{wt}}$-N2A(NC VPA:0.68 $\pm 0.23 \mathrm{~cm}^{3}$ vs.NC:1.45+/-0.40 $\left.\mathrm{cm}^{3}, \mathrm{p}<0.0001\right)$ but did not have effect on Srr ${ }^{\mathrm{kd}}-\mathrm{N} 2 \mathrm{~A}-$ derived tumors(sh445 VPA:2.18+/-0.38 $\mathrm{cm}^{3}$ vs.sh445 2.15+/-0.37 $\mathrm{cm}^{3}, \mathrm{p}=0.561$ )(Figures.6A and 6D). Regarding the weights,VPA injection significantly reduced the tumor weights from Srrvt-N2A(NC VPA:0.42+/-0.11g vs.NC:0.98+/-0.1g,p<0.0001) but did not have effect on $\mathrm{Sr}^{\mathrm{kd}}$-N2A-derived tumors(sh445 VPA:1.32 $\pm 0.24 \mathrm{~g} v s$. sh445 1.24+/-0.2g, $\mathrm{p}=0.25$ ), compared with vehicle(Figures.6B and 6D). In the tumors,knockdown of SR obviously reduced SR expression and VPA treatment induced SR expression in the tumors(Figures.6C and 6E).

\section{High SR expression was associated with better prognosis with R2 analysis}

To predict the relationship between SR expression and the prognosis in neuroblastoma patients,the program of R2:Genomics Analysis and Visualization Platform(http://r2.amc.nl) with Kaplan scanning was used. With this method,we found that high expression of SR was associated with good prognosis whereas low expression of SR was coupled with low probability of survival(Figure.7). For example,the patients with high expression of SR have above 95\% probability of survival during the 24-168 months follow-up whereas the patients with low expression of SR have only around $60 \%$ probability to survival 
during the 24 months follow-up;the survival rate dramatically reduced to around $55 \%$ between $48-216$ months follow-up in the group with low level of SR expression(Figure.7).

\section{Discussion}

In the whole,we found that in vitro,induced expression of SR mediated differentiation of neuroblastoma cells whereas knockdown of SR mitigated differentiation and increased proliferation under VPA induction. These effects were confirmed by use of a neuroblastoma model. In transplantation experiment,VPA reduced the sizes and weights of Srrtrt-N2A-derived neuroblasotma but did not have effect on Srrd-N2Aderived tumors. With R2 program,SR expression was linked with high survival whereas low expression of SR was coupled with low level of survival.

Induction of differentiation has shown efficacy in neuroblastoma therapy. For example,application of histone deacetylase inhibitors(HDACi) has emerged as a potential strategy to treat neuroblastoma because of their capacities to inhibit tumor proliferation,or induce differentiation,apoptosis and cell cycle arrest in neuroblastoma (27-30). VPA is a HDACi and a cell differentiator as well. Our recent study suggests that the differentiation effect accounts for SR expression since under undifferentiaton condition,VPA do not increase SR expression(26). The effect of VPA on SR expression is dependent on its differentiation effect rather than the effect of HDAC inhibition. Further, we indicated all-trans retinoic acid,a differentiator of neural precursor cells,increased SR expression,consolidating that SR expression is associated with differentiation. In combination with the observation that knockdown of SR promoted proliferation and cell cycle entry,we conclude that SR expression mediates N2A differentiation. We indicated that SR expression modulated cell proliferation and differentiation of neuroblastoma cells,the coupling between elevation of SR expression and the differentiation was in coincidence with previous reports $(11,12)$. Particularly,differentiation of P19 cells is coupled with SR expression but is not overcome by inhibiting D-serine synthesis(12). In this study,addition of D-serine did not rescue differentiation deficit in SR-knockdown neurons. We consider that unknown proteins interacting with SR may mediate the differentiation deficit. At least,we clarified that modulation of cell cycle-related protein accounted for the differentiation defect under the context of SR knockdown.

Cell cycle is determined by balanced expression of cell cycle-promoting proteins such as cyclin,cyclindependent kinases(CDK) and cell cycle-blocking proteins such as P2 $7^{\mathrm{Kip} 1}$ and P21. In neuroblastoma cells,P27 ${ }^{\mathrm{Kip} 1}$ plays roles in inducing cell cycle exit and differentiation via diverse mechanisms(31) by interacting with cyclin and CDK, blocking entry into cell cycle or stabilizing NG2,a transcriptional factor,promoting differentiation(31). Compared with $\mathrm{Sr}^{\mathrm{wt}}-\mathrm{N} 2 \mathrm{~A}$ cells, $\mathrm{Sr}^{\mathrm{kd}}-\mathrm{N} 2 \mathrm{~A}$ contained lower level of $\mathrm{P} 27^{\mathrm{Kip} 1}$ versus higher level of CyclinD1,a G1/S transitional cyclin,under the induction of VPA. The expression pattern suggests that increased expression of SR promote cell cycle exit which was depended on regulation of cell cycle-related proteins. However, the mechanism by which SR modulates the expression of cell cycle-related proteins is yet unclear. 
Upregulation of SR is connected with neurodegenerative diseases such as Alzheimer' disease(3236), amytrophic lateral sclerosis(37), and diabetic retinopathy(38-40) in which excitoxicity is a common mechanism whereas downregulation of SR has been majorly connected with schizophrenia $(7,8)$,due to that deficiency of SR impacts dendrite development during early stage of neuronal development. The mechanism by which deficiency of SR mediates neuronal development delay underlying schizophrenia is unclear. Basing on this study,we propose that deficiency of SR regulates the expression of cell cyclerelated proteins and affects neuronal development,thereby leading to less elaborate dendrite arbor in SRdeficient schizophrenia model.

In summary,we indicated that SR expression determined whether N2A underwent proliferation and differentiation and further dissected the mechanism. Further,we indicated that VPA treatment mitigated growth of neuroblastoma by inducing SR expression which suggests that induction of SR expression may be a novel strategy to treat neuroblastoma.

\section{Declarations}

\section{Acknowledgments}

The study was supported by Zhejiang Provincial Natural Science Foundation,China (ID\#LY19H090011) to Dr. He Zhang and start-up funding (QTJ19019) from Wenzhou Medical University to Dr. Jinfang Lu. The study was also supported by the integrated project of State Key Laboratory of Ophthalmology,Optometry, and Visual Science; Wenzhou Medical University,China(Funding number\#J0220190204).

\section{Data availability}

All the data were contained in the main text and in the supplemented materials.

\section{Conflict of interest}

All the authors have found none to disclaim. 


\section{References}

1. Foltyn VN, Bendikov I, De Miranda J, Panizzutti R, Dumin E, Shleper M, et al. Serine racemase modulates intracellular D-serine levels through an alpha,beta-elimination activity. J Biol Chem $2005 \mathrm{Jan}$ $21 ; 280$ (3): 1754-1763.

2. Matsui T, Sekiguchi M, Hashimoto A, Tomita U, Nishikawa T, Wada K. Functional comparison of Dserine and glycine in rodents: the effect on cloned NMDA receptors and the extracellular concentration. $J$ Neurochem 1995 Jul; 65 (1): 454-458.

3. Schell MJ, Molliver ME, Snyder SH. D-serine, an endogenous synaptic modulator: localization to astrocytes and glutamate-stimulated release. Proc Natl Acad Sci U S A 1995 Apr 25; 92 (9): 3948-3952.

4. Mothet JP, Parent AT, Wolosker H, Brady RO, Jr., Linden DJ, Ferris CD, et al. D-serine is an endogenous ligand for the glycine site of the N-methyl-D-aspartate receptor. Proc Natl Acad Sci U S A 2000 Apr 25; 97 (9): 4926-4931.

5. Kim PM, Aizawa H, Kim PS, Huang AS, Wickramasinghe SR, Kashani AH, et al. Serine racemase: activation by glutamate neurotransmission via glutamate receptor interacting protein and mediation of neuronal migration. Proc Natl Acad Sci U S A 2005 Feb 8; 102 (6): 2105-2110.

6. Zhang $\mathrm{H}$, Song $\mathrm{L}$, Chang $\mathrm{Y}, \mathrm{Wu} \mathrm{M}$, Kuang $\mathrm{X}$, Jiang $\mathrm{H}$, et al. Potential deficit from decreased cerebellar granule cell migration in serine racemase-deficient mice is reversed by increased expression of GluN2B and elevated levels of NMDAR agonists. Mol Cell Neurosci 2017 Dec; 85: 119-126.

7. Labrie V, Fukumura R, Rastogi A, Fick LJ, Wang W, Boutros PC, et al. Serine racemase is associated with schizophrenia susceptibility in humans and in a mouse model. Human molecular genetics 2009 Sep 1; 18 (17): 3227-3243.

8. Ma TM, Abazyan S, Abazyan B, Nomura J, Yang C, Seshadri S, et al. Pathogenic disruption of DISC1serine racemase binding elicits schizophrenia-like behavior via D-serine depletion. Molecular psychiatry 
2013 May; 18 (5): 557-567.

9. Balu DT, Coyle JT. Neuronal D-serine regulates dendritic architecture in the somatosensory cortex. Neuroscience letters 2012 May 31; 517 (2): 77-81.

10. Balu DT, Li Y, Puhl MD, Benneyworth MA, Basu AC, Takagi S, et al. Multiple risk pathways for schizophrenia converge in serine racemase knockout mice, a mouse model of NMDA receptor hypofunction. Proc Natl Acad Sci U S A 2013 Jun 25; 110 (26): E2400-2409.

11. Inoue R, Yoshihisa Y, Tojo Y, Okamura C, Yoshida Y, Kishimoto J, et al. Localization of serine racemase and its role in the skin. J Invest Dermatol 2014 Jun; 134 (6): 1618-1626.

12. Fuchs SA, Roeleveld MW, Klomp LW, Berger R, de Koning TJ. D-serine influences synaptogenesis in a p19 cell model. JIMD Rep 2012; 6: 47-53.

13. Ohshima K, Nojima S, Tahara S, Kurashige M, Kawasaki K, Hori Y, et al. Serine racemase enhances growth of colorectal cancer by producing pyruvate from serine. Nat Metab 2020 Jan; 2 (1): 81-96.

14. Huang M, Weiss WA. Neuroblastoma and MYCN. Cold Spring Harb Perspect Med 2013 Oct 1; 3 (10): a014415.

15. Maris JM, Hogarty MD, Bagatell R, Cohn SL. Neuroblastoma. Lancet 2007 Jun 23; 369 (9579): 21062120 .

16. Cohn SL, Pearson AD, London WB, Monclair T, Ambros PF, Brodeur GM, et al. The International Neuroblastoma Risk Group (INRG) classification system: an INRG Task Force report. J Clin Oncol 2009 Jan 10; 27 (2): 289-297. 
17. Bosse KR, Maris JM. Advances in the translational genomics of neuroblastoma: From improving risk stratification and revealing novel biology to identifying actionable genomic alterations. Cancer 2016 Jan $1 ; 122$ (1): 20-33.

18. Jiang M, Stanke J, Lahti JM. The connections between neural crest development and neuroblastoma. Curr Top Dev Biol; 2011 94: 77-127.

19. Janoueix-Lerosey I, Lequin D, Brugieres L, Ribeiro A, de Pontual L, Combaret V, et al. Somatic and germline activating mutations of the ALK kinase receptor in neuroblastoma. Nature 2008 Oct 16; 455 (7215): 967-970.

20. George RE, Sanda T, Hanna M, Frohling S, Luther W, 2nd, Zhang J, et al. Activating mutations in ALK provide a therapeutic target in neuroblastoma. Nature 2008 Oct 16; 455 (7215): 975-978.

21. Newman EA, Nuchtern JG. Recent biologic and genetic advances in neuroblastoma: Implications for diagnostic, risk stratification, and treatment strategies. Semin Pediatr Surg Oct 2016; 25 (5): 257-264.

22. Kohl NE, Kanda N, Schreck RR, Bruns G, Latt SA, Gilbert F, et al. Transposition and amplification of oncogene-related sequences in human neuroblastomas. Cell 1983 Dec; 35 (2 Pt 1): 359-367.

23. Stanton LW, Schwab M, Bishop JM. Nucleotide sequence of the human N-myc gene. Proc Natl Acad Sci U S A 1986 Mar; 83 (6): 1772-1776.

24. Chen Y, Takita J, Choi YL, Kato M, Ohira M, Sanada M, et al. Oncogenic mutations of ALK kinase in neuroblastoma. Nature 2008 Oct 16; 455 (7215): 971-974.

25. Muth D, Ghazaryan S, Eckerle I, Beckett E, Pohler C, Batzler J, et al. Transcriptional repression of SKP2 is impaired in MYCN-amplified neuroblastoma. Cancer Res 2010 May 1; 70 (9): 3791-3802. 
26. Zhang H, Lu J, Wu S. Sp4 controls constitutive expression of neuronal serine racemase and NF-E2related factor-2 mediates its induction by valproic acid. Biochim Biophys Acta Gene Regul Mech 2020 Sep; 1863 (9): 194597.

27. Bolden JE, Peart MJ, Johnstone RW. Anticancer activities of histone deacetylase inhibitors. Nat Rev Drug Discov 2006 Sep; 5 (9): 769-784.

28. Hahn CK, Ross KN, Warrington IM, Mazitschek R, Kanegai CM, Wright RD, et al. Expression-based screening identifies the combination of histone deacetylase inhibitors and retinoids for neuroblastoma differentiation. Proc Natl Acad Sci U S A 2008 Jul 15; 105 (28): 9751-9756.

29. Muhlethaler-Mottet A, Meier R, Flahaut M, Bourloud KB, Nardou K, Joseph JM, et al. Complex molecular mechanisms cooperate to mediate histone deacetylase inhibitors anti-tumour activity in neuroblastoma cells. Mol Cancer 2008 Jun 12; 7: 55.

30. Oehme I, Deubzer HE, Wegener D, Pickert D, Linke JP, Hero B, et al. Histone deacetylase 8 in neuroblastoma tumorigenesis. Clin Cancer Res 2009 Jan 1; 15 (1): 91-99.

31. Nguyen L, Besson A, Roberts JM, Guillemot F. Coupling cell cycle exit, neuronal differentiation and migration in cortical neurogenesis. Cell Cycle 2006 Oct; 5 (20): 2314-2318.

32. Balu DT, Pantazopoulos H, Huang CCY, Muszynski K, Harvey TL, Uno Y, et al. Neurotoxic astrocytes express the d-serine synthesizing enzyme, serine racemase, in Alzheimer's disease. Neurobiology of disease 2019 Oct; 130: 104511.

33. Madeira C, Lourenco MV, Vargas-Lopes C, Suemoto CK, Brandao CO, Reis T, et al. d-serine levels in Alzheimer's disease: implications for novel biomarker development. Transl Psychiatry 2015; 5: e561. 
34. Wu SZ, Bodles AM, Porter MM, Griffin WS, Basile AS, Barger SW. Induction of serine racemase expression and D-serine release from microglia by amyloid beta-peptide. J Neuroinflammation 2004 Apr 20; 1 (1): 2.

35. Wu S, Basile AS, Barger SW. Induction of serine racemase expression and D-serine release from microglia by secreted amyloid precursor protein (sAPP). Curr Alzheimer Res 2007 Jul; 4 (3): 243-251.

36. Piubelli L, Pollegioni L, Rabattoni V, Mauri M, Princiotta Cariddi L, Versino M, et al. Serum D-serine levels are altered in early phases of Alzheimer's disease: towards a precocious biomarker. Transl Psychiatry 2021 Jan 26; 11 (1): 77.

37. Sasabe J, Chiba T, Yamada M, Okamoto K, Nishimoto I, Matsuoka M, et al. D-serine is a key determinant of glutamate toxicity in amyotrophic lateral sclerosis. EMBO J 2007 Sep 19; 26 (18): 41494159 .

38. Jiang H, Fang J, Wu B, Yin G, Sun L, Qu J, et al. Overexpression of serine racemase in retina and overproduction of D-serine in eyes of streptozotocin-induced diabetic retinopathy. $J$ Neuroinflammation 2011 Sep 22; 8 (1): 119.

39. Jiang H, Du J, Song J, Li Y, Wu M, Zhou J, et al. Loss-of-function mutation of serine racemase attenuates retinal ganglion cell loss in diabetic mice. Exp Eye Res 2018 Jun 18; 175: 90-97.

40. Jiang $H$, Zhang $H$, Jiang $X$, Wu S. Overexpression of D-amino acid oxidase prevents retinal neurovascular pathologies in diabetic rats. Diabetologia 2021 Mar; 64 (3): 693-706.

\section{Figures}




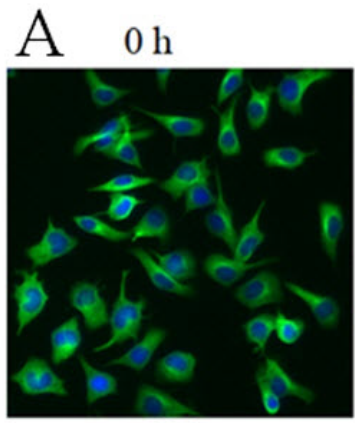

$72 \mathrm{~h}$

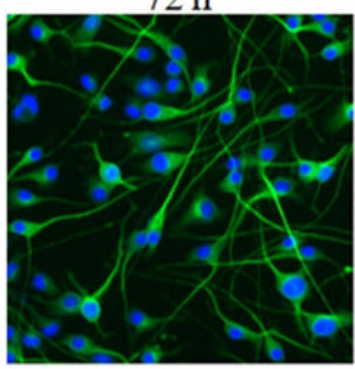

$24 \mathrm{~h}$

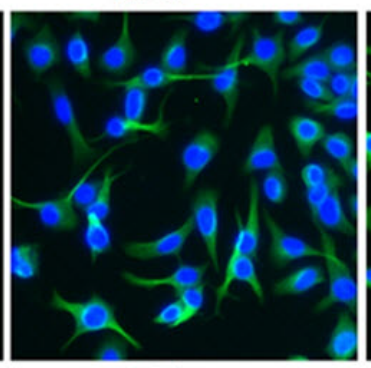

$96 \mathrm{~h}$

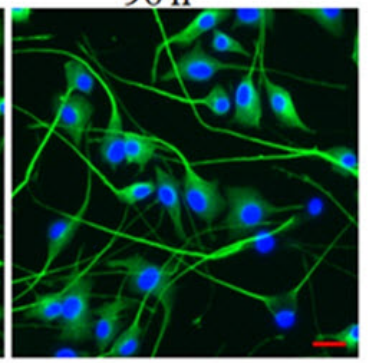

$48 \mathrm{~h}$

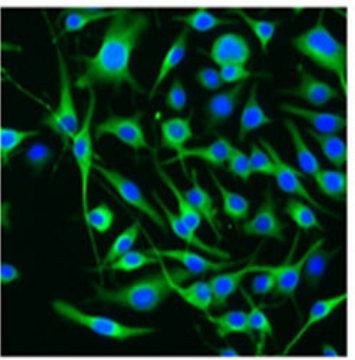

$\mathrm{B}$

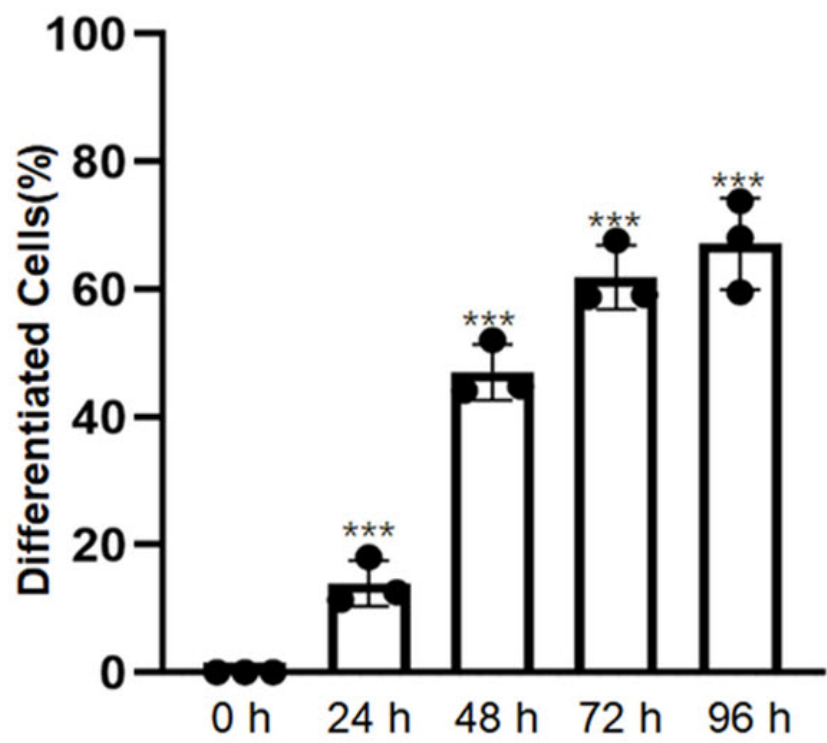

Figure 1

VAP induced N2A differentiation. A,N2A cells were coated on coverslip sitting in 12-well plate at the density of 80,000 cells/well,cultured in DMEM plus $10 \%$ FBS. After 24 hours, the culture media were switched into DMEM plus $1 \%$ FBS containing $1 \mathrm{mM}$ VPA. The cells were fixed with $4 \%$ paraformaldehyde at different timepoints(24-96 hours) of treatment and subject to immunofluorescence with BIIItubulin(1:200). DAPI staining was used to indicate nuclei. The images from triplicate culture preparations

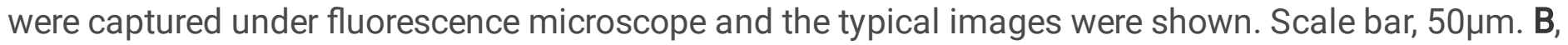
The cells were defined as differentiated neurons when the values of neurite lengths were bigger than twofold the values of soma diameter. The percentages of differentiated cells were calculated as the ratios between differentiated neurons and DAPI-staining cells in the same field. The percentage of differentiated neurons were obtained from 15 randomly selected fields for each preparation,at least 50 cells in each field. ${ }^{* \star} p<0.0001$ indicated the differences between treatments $v s$. non-treatment,respectively. One-way ANOVA was used to compare the differences. 


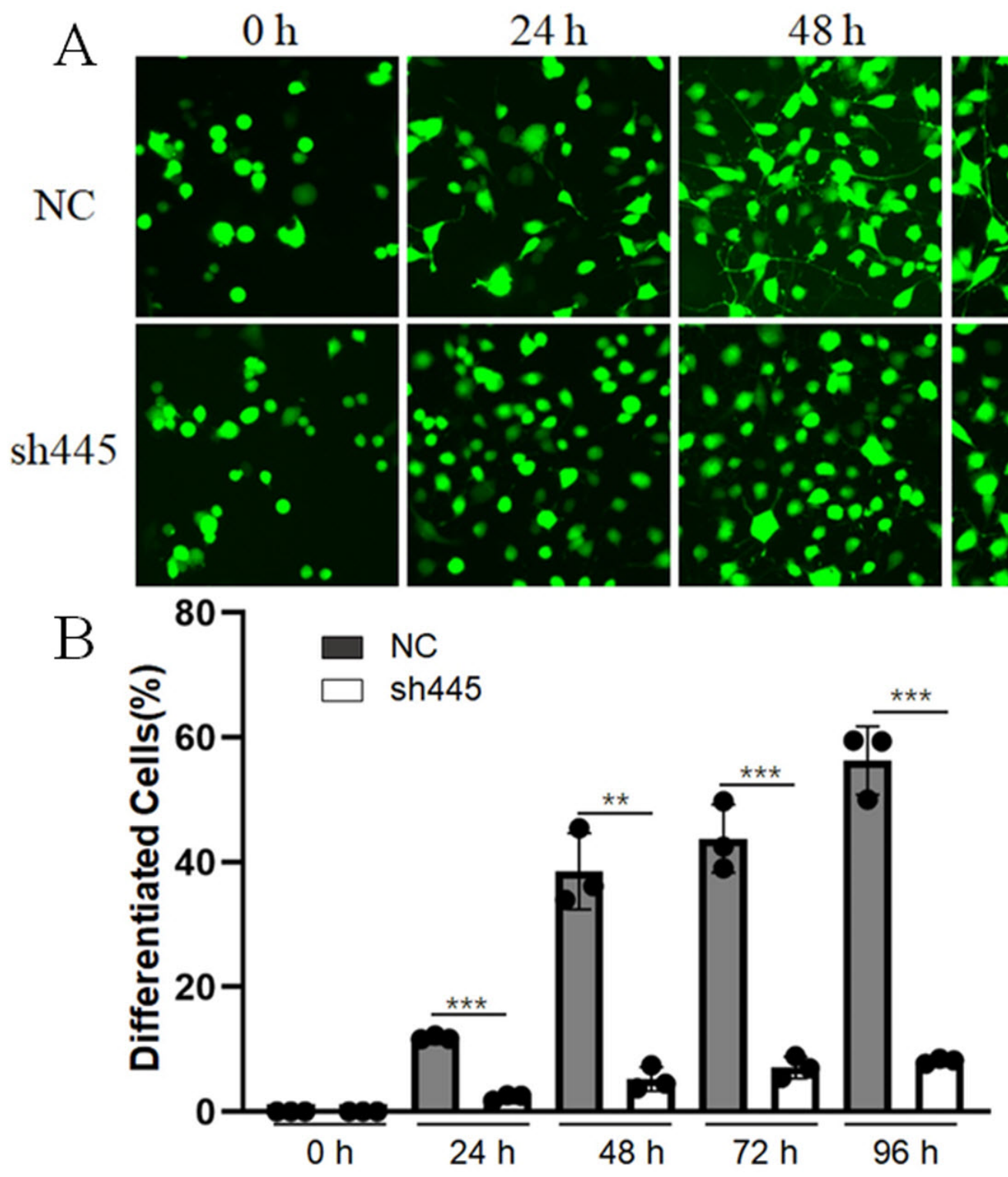

Figure 2

Stable knockdown of SR inhibited neuronal differentiation. The $S r^{\mathrm{kd}}-\mathrm{N} 2 \mathrm{~A}(\mathrm{sh} 445)$ or $\mathrm{Sr}^{\mathrm{wt}} \mathrm{N} 2 \mathrm{~A}$ neurons(NC) were plated in 150,000 cells/well in 6-well plates,cultured in DMEM plus 10\% FBS. After 24 hours, the culture media were switched into DMEM plus 1\% FBS containing $1 \mathrm{mM}$ VPA. After treatment by VPA between 0-96 hours,the images were acquired under fluorescence microscope. Scale bar,50 $\mu \mathrm{m}$. B,The differentiated neurons were quantified as described in the materials and methods. The percentages of differentiated neurons were calculated as the ratios between differentiated neurons and total neurons. The ratios were averaged from triplicate culture preparations and 9-15 randomly selected fields were quantified for each culture preparation in each timepoint. The numbers of the percentage of differentiated neurons in $\mathrm{Srr}^{\mathrm{kd}}-\mathrm{N} 2 \mathrm{~A}$ were lower than those of $\mathrm{Sr}^{\mathrm{rt}}{ }_{-}^{\mathrm{N}} \mathrm{N} 2 \mathrm{~A}$ neurons. At 24,72, and 96 hours of treatments, $S r r^{\mathrm{kd}} \mathrm{N} 2 \mathrm{~A} v s . S r^{\mathrm{wt}} \mathrm{N} 2 \mathrm{~A}, \mathrm{p}<0.0001$, respectively. At 48 hour of treatment, $S r r^{\mathrm{kd}} v s . S r^{\mathrm{wt}}, \mathrm{p}=0.001$. Student's t-test was used to compare the difference between $S r r^{\mathrm{kd}}$ and $S r r^{\mathrm{wt}}$ at each timepoint. 

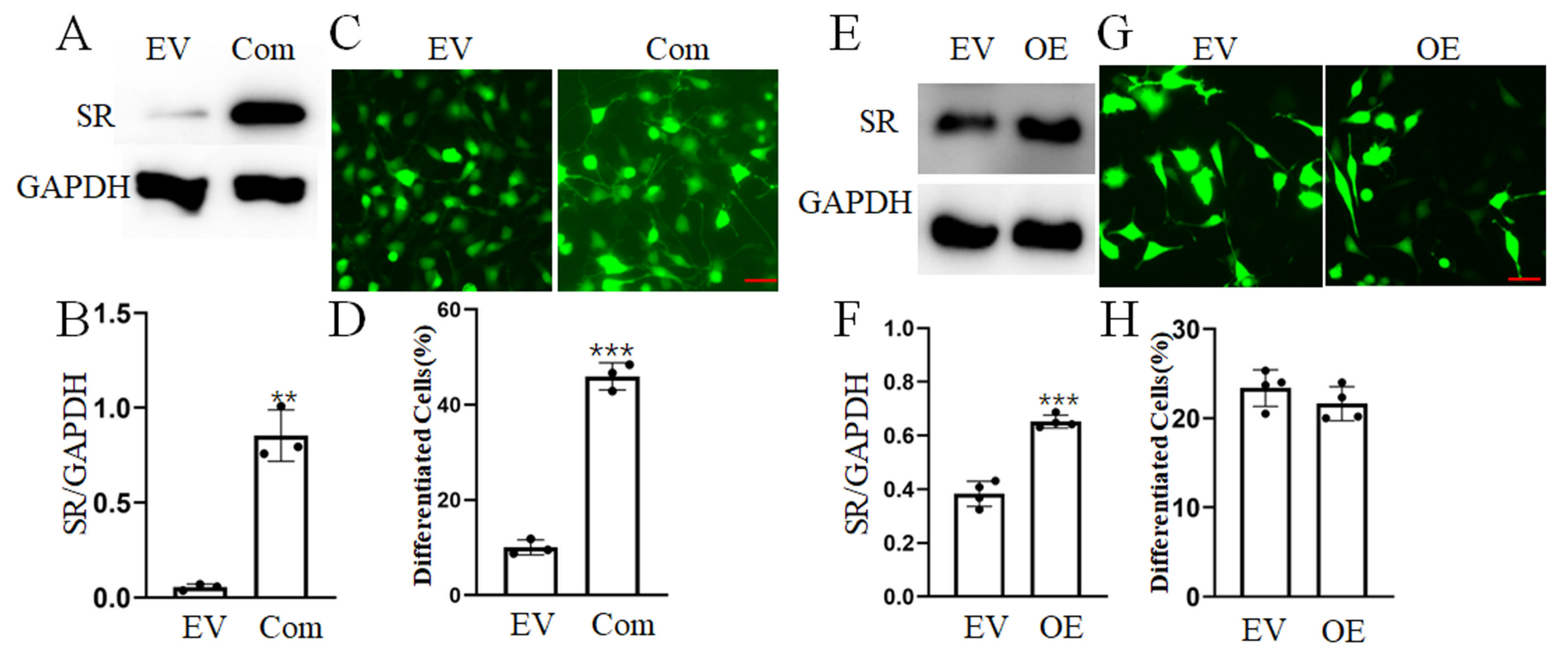

Figure 3

Overexpression of SR rescued the differentiation deficit in $S r^{\mathrm{kd}}-\mathrm{N} 2 \mathrm{~A}$ cells but did not promote differentiation in $S r^{\mathrm{wt}} \mathrm{N} 2 \mathrm{~A}$ neurons. A,The $S \mathrm{Sr}^{\mathrm{kd}}-\mathrm{N} 2 \mathrm{~A}(\mathrm{sh} 445)$ were plated in 6-well plates at the density of 400,000 cells/well,cultured in DMEM plus 10\% FBS. After 24 hours in culture,the cells were transiently transfected with $2 \mu \mathrm{g} /$ well empty vector(EV) or equal amount of SR-expressing plasmid,in DMEM,for 4 hours. After the transfection,the media were switched into DMEM plus 1\% FBS containing $1 \mathrm{mM}$ VPA. After 48 hours, the cells were harvested for immunoblotting against SR and an internal-loading control,GAPDH. B,Transient transfection of SR-expressing plasmid(Com) increased SR expression compared with transfection of empty vector(EV). The results were averaged from triplicate culture preparations. ${ }^{*} \mathrm{p}=0.009$. C and $\mathrm{D}$, Transient transfection of SR-expressing plasmid(Com) increased neuronal differentiation compared with transfection of empty vector(EV) in Sr ${ }^{\mathrm{kd}}$-N2A neurons,under VPA induction. The ratios were averaged from triplicate culture preparations and 9-15 randomly selected fields

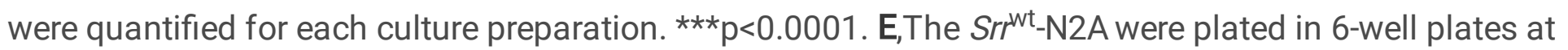
the density of 400,000 cells/well,cultured in DMEM plus 10\% FBS. After 24 hours in culture,the cells were transiently transfected with $2 \mu \mathrm{g} /$ well empty vector(EV) and equal amount of SR-expressing plasmid to overexpress SR(OE),in DMEM,for 4 hours. After the transfection,the media were switched into DMEM plus $1 \%$ FBS containing $1 \mathrm{mM}$ VPA. After 48 hours,the cells were harvested for immunoblotting against SR. F,Transient transfection of SR-expressing plasmid(OE) increased SR expression compared with transfection of empty vector(EV). The results were averaged from triplicate culture preparations. $* \star \star p<0.0001$. $\mathbf{G}$ and $\mathbf{H}$, Transient transfection of SR-expressing plasmid(OE) did not increase differentiation compared with transfection of empty vector(EV) in Srr ${ }^{\text {wt }}-\mathrm{N} 2 \mathrm{~A}$ neurons, under VPA induction. The ratios were averaged from triplicate culture preparations and 9-15 randomly selected fields were quantified for each culture preparation. $p=0.254$. 

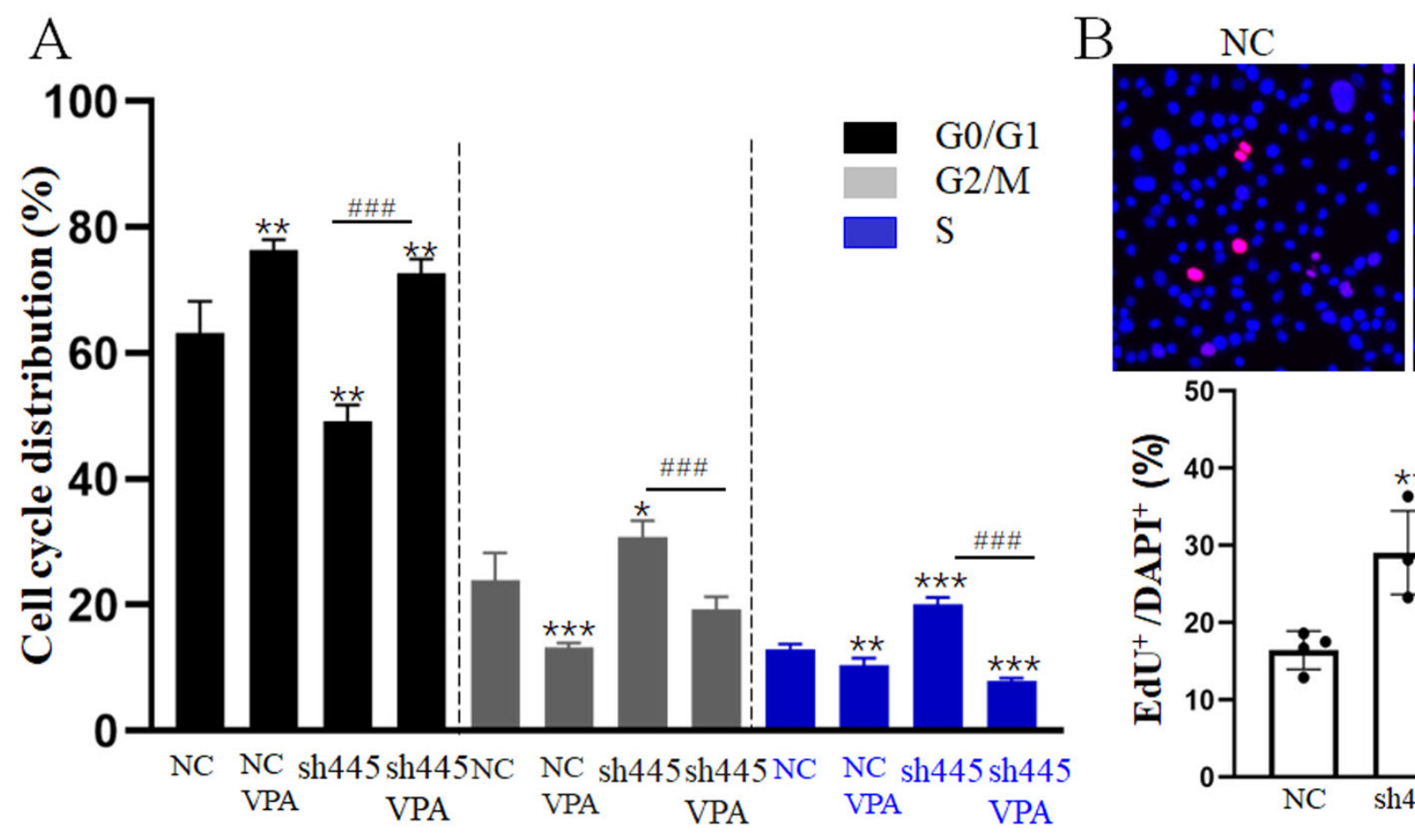

$\operatorname{sh} 445$

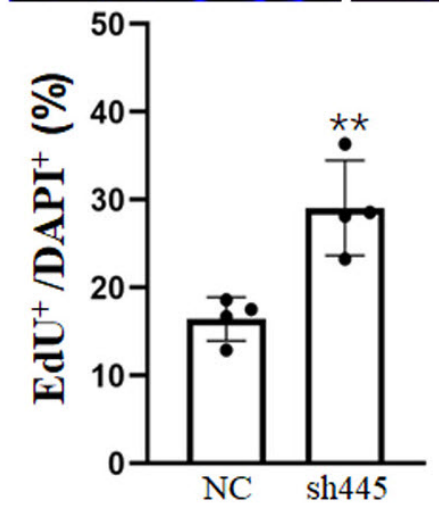

Figure 4

Stable knockdown of SR promoted cell proliferation and cell cycle entry. A,The Srr ${ }^{\mathrm{kd}}-\mathrm{N} 2 \mathrm{~A}(\mathrm{sh} 445)$ or $\mathrm{Sr} \mathrm{r}^{\mathrm{wt}}$ N2A neurons(NC) were subject to cell cycle analysis as described in the materials and methods. In G0/G1 phase,NC VPA vs. NC, ${ }^{* *} p<0.0001$; sh445 VPA vs.sh445,\#\#\#p<0.0001;sh445 vs.NC, ${ }^{* * p}<0.001$;sh445 VPA vs.NC, ${ }^{\star *} p<0.001$. In G2/M phase,NC VPA vs.NC, ${ }^{\star \star *} p<0.0001 ;$ sh445 VPA vs.sh445, \#\#\#p<0.0001;sh445

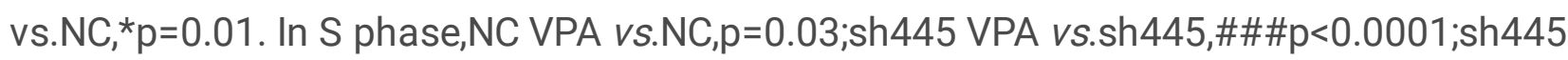
vs.NC, ${ }^{\star \star \star} \mathrm{p}<0.0001 ;$ sh445 VPA vs.NC, ${ }^{\star \star *} \mathrm{p}<0.0001$. B,top panel,The Srr ${ }^{\mathrm{kd}}-\mathrm{N} 2 \mathrm{~A}(\mathrm{sh} 445)$ or Srr ${ }^{\mathrm{vt}}$-N2A neurons(NC) were coated in coverslips sitting in 12-well plates at the density of 100,000 cells/well. After cultured in DMEM plus 10\% FBS for 24 hours, the media were switched into DMEM plus $1 \%$ FBS containing $1 \mathrm{mM}$ VPA. After 48 hours in culture,the EdU dye $(10 \mu \mathrm{M})$ was added to the culture and incubated for 2 hours. The cells were fixed and stained according to the manufacturer's manual. DAPI was used to indicate nuclei. The images were acquired under fluorescence microscope. The images were typical of quadruplicate culture preparations. Low panel,the cells positive for EdU staining were counted and the proliferation was represented as the ratios between the numbers of $\mathrm{EdU}^{+}$cells and the numbers of $\mathrm{DAPI}^{+}$cells. The ratios were averaged from 9-15 randomly selected fields in each culture preparations. $\star \star x=0.005$. 


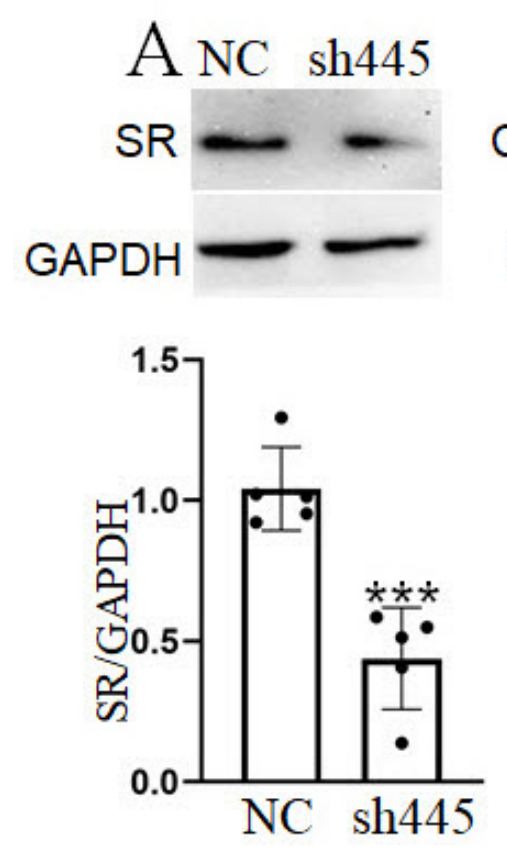

E $\quad \mathrm{NC} \operatorname{sh} 445$
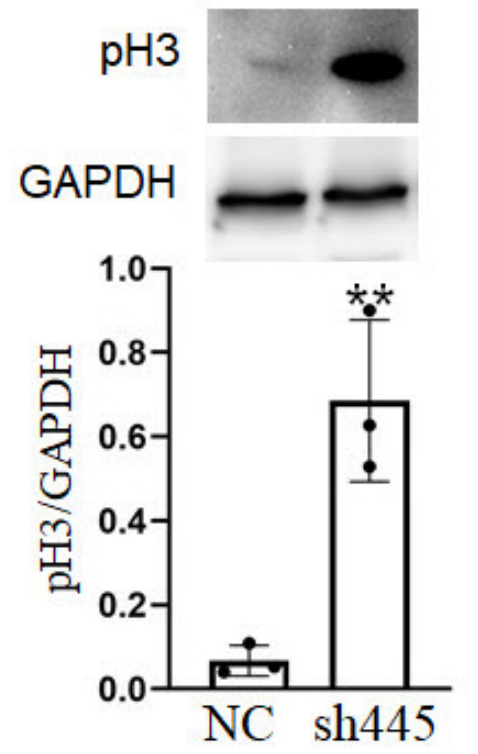

B NC sh445

CyclinD1

GAPDH

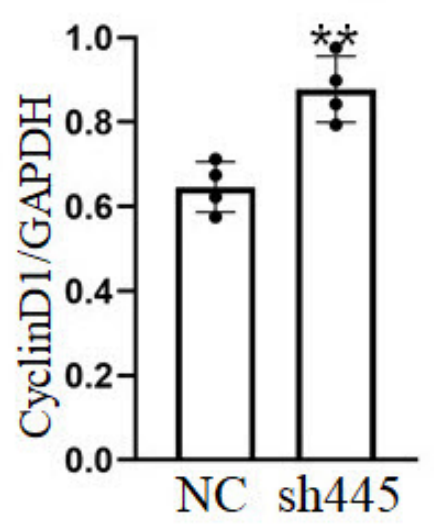

F NC $\quad$ sh 445

$\mathrm{pRb}$
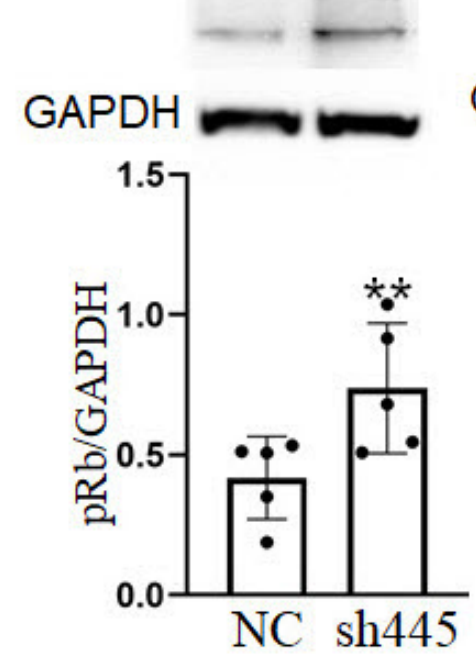

C NC $\operatorname{sh} 445$

P21

GAPDH

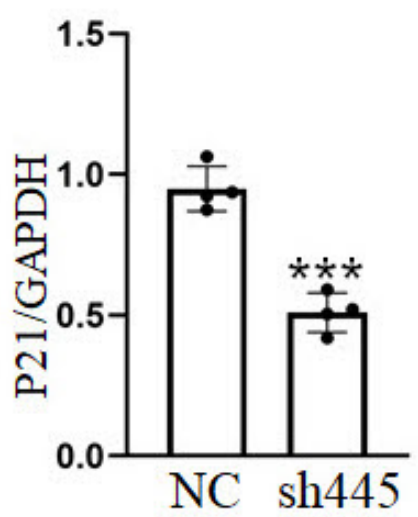

G NC $\operatorname{sh} 445$

Ki67

D NC $\operatorname{sh} 445$

P27

GAPDH

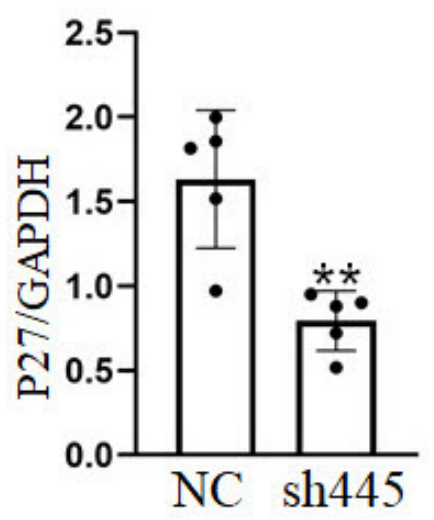

GAPDH

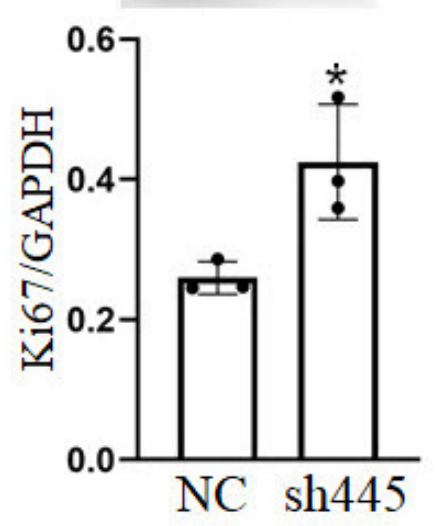

Figure 5

Stable knockdown of SR modulated expression of cell cycle-related proteins. The $\mathrm{Srr}^{\mathrm{kd}} \mathrm{N} 2 \mathrm{~N}$ (sh445) or $\mathrm{Sr}^{\mathrm{wt} \mathrm{Nt}} \mathrm{N} 2 \mathrm{~A}$ neurons(NC) was plated in 6-well plates at the density of 400,000 cells/well. After cultured in DMEM plus $10 \%$ FBS for 24 hours, the media were switched into DMEM plus $1 \%$ FBS containing $1 \mathrm{mM}$ VPA. After 48 hours in culture,the cells were harvested for immunoblotting. Knockdown of SR in $S_{r}{ }^{k d}$ (sh445)-N2A decreased SR, ${ }^{\star \star \star} p<0.0001(A)$; increased CyclinD1, ${ }^{\star \star} \mathrm{p}=0.003(\mathrm{~B})$; decreased $P 21,{ }^{\star \star *} p<0.0001$ (C);decreased P27, ${ }^{* \star} p=0.003\left(\right.$ D);increased $p H 3,{ }^{* \star} p=0.005$ (E);increased $p-R B$, ${ }^{* \star} \mathrm{p}=0.0032(\mathbf{F})$;increased $\mathrm{Ki67},{ }^{*} \mathrm{p}=0.029(\mathbf{G})$,relative to those in Srr ${ }^{\mathrm{wt}} \mathrm{N} 2 \mathrm{~A}$ neurons. Student's $t$-test was used to compare the differences. 

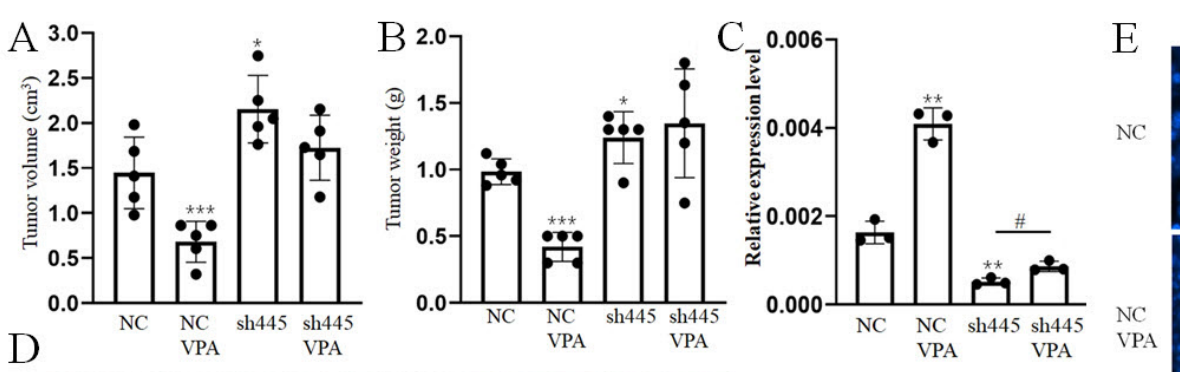

DAPI
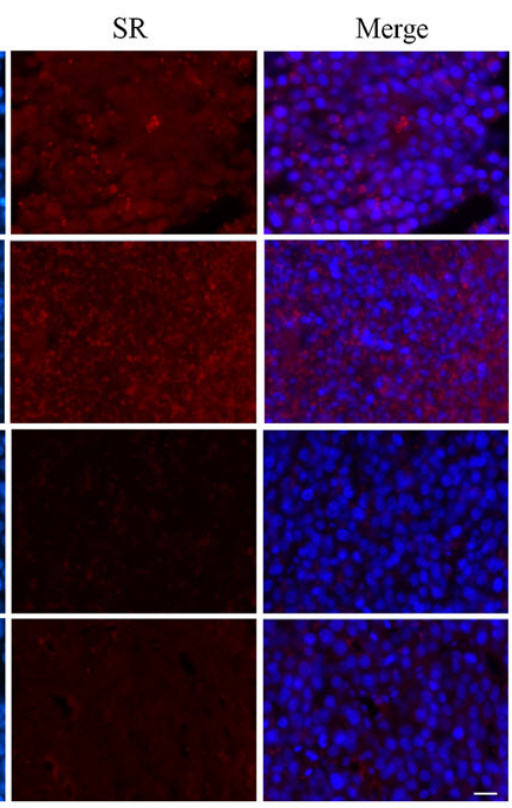

Figure 6

Stable knockdown of SR promoted tumor growth and VPA mitigated the growth in Sirt - N2A-derived tumors but not in $\mathrm{Sr}^{\mathrm{kd}}{ }^{\mathrm{N}} \mathrm{N} 2 \mathrm{~A}(\mathrm{sh} 445)$-derived tumors. Establishment of neuroblastoma model with nude mice was conducted as described in the materials and methods. Two weeks after injection of VPA or PBS, the mice were subject to euthanization. The tumors were excised and the volumes were measured with a caliper(A) and the weights were evaluated by use of an analytic balance(B). A, The volumes of the sh445-derived tumors(sh445,2.15+/-0.37 $\mathrm{cm}^{3}$ ) were bigger than those of the $S \mathrm{Sr}{ }^{\mathrm{Nt}}$-derived tumors $\left(\mathrm{NC}, 1.45+/-0.40 \mathrm{~cm}^{3}\right)\left({ }^{*} \mathrm{p}=0.02\right)$. VPA injection reduced tumor sizes in NC(NC VPA, $\left.0.68+/-0.23 \mathrm{~cm}^{3}\right)$ compared with PBS injection(NC) $(\star \star \star p<0.0001)$ whereas VPA injection did not reduced tumor sizes in sh445 mice(sh445 VPA,2.18+/-0.38 $\left.\mathrm{cm}^{3}\right)$ compared with PBS injection(sh445)( $\left.\mathrm{p}=0.561\right)$. B, The values of the weights of the sh445-derived tumors(sh445,1.24+/-0.2g) were bigger than $\mathrm{Srr}^{\mathrm{wt}}$-derived tumors $(\mathrm{NC}, 0.98+/-0.1 \mathrm{~g})$ ( $\left.{ }^{\star} \mathrm{p}=0.03\right)$. VPA injection reduced tumor in NC(NC VPA, $\left.0.42+/-0.11 \mathrm{~g}\right)$ compared with PBS injection(NC) $\left.{ }^{* * *} p<0.0001\right)$ whereas VPA injection did not reduce tumor in sh445 mice $($ sh445 VPA, $1.32+/-0.24 \mathrm{~g})$ compared with PBS injection(sh445) $(\mathrm{p}=0.25)$. The values were averaged from tumors isolated from five mice in each group. One-way ANOVA was used to compare the differences. C,The excised tissues from tumors were also subject to qRT-PCR to evaluate the levels of Srr mRNA. SrrmRNA levels in sh445-derived tumor were lower than NC(**p=0.002). VPA injection increased SrrmRNA levels in $\mathrm{NC}\left({ }^{*} \mathrm{p}=0.001\right)$ or in sh445-derived tumors $(\# \mathrm{p}=0.015)$,relative to PBS injection, respectively. The results were averaged from tissues isolated from three mice. One-way ANOVA was used to compare the differences. D,The tumors isolated from PBS-injection Srivt N2A-derived neuroblastoma mice(NC),VPAinjection $\mathrm{Sr}^{\mathrm{wt}} \mathrm{N} 2 \mathrm{~A}$-derived neuroblastoma mice(NC VPA), PBS-injection sh445 N2A-derived neuroblastoma mice(sh445), and VPA-injection sh445 N2A-derived neuroblastoma mice(sh445 VPA) were displayed. E,The isolated tissues from tumors were made into paraffin-embedded sections and were immunoblotted against SR for the tissues. DAPI was used to indicate nuclei and SR staining and DAPI 
staining were merged in the last column. Omitting the primary antibody did not produce staining. Scale bar, $50 \mu \mathrm{m}$.

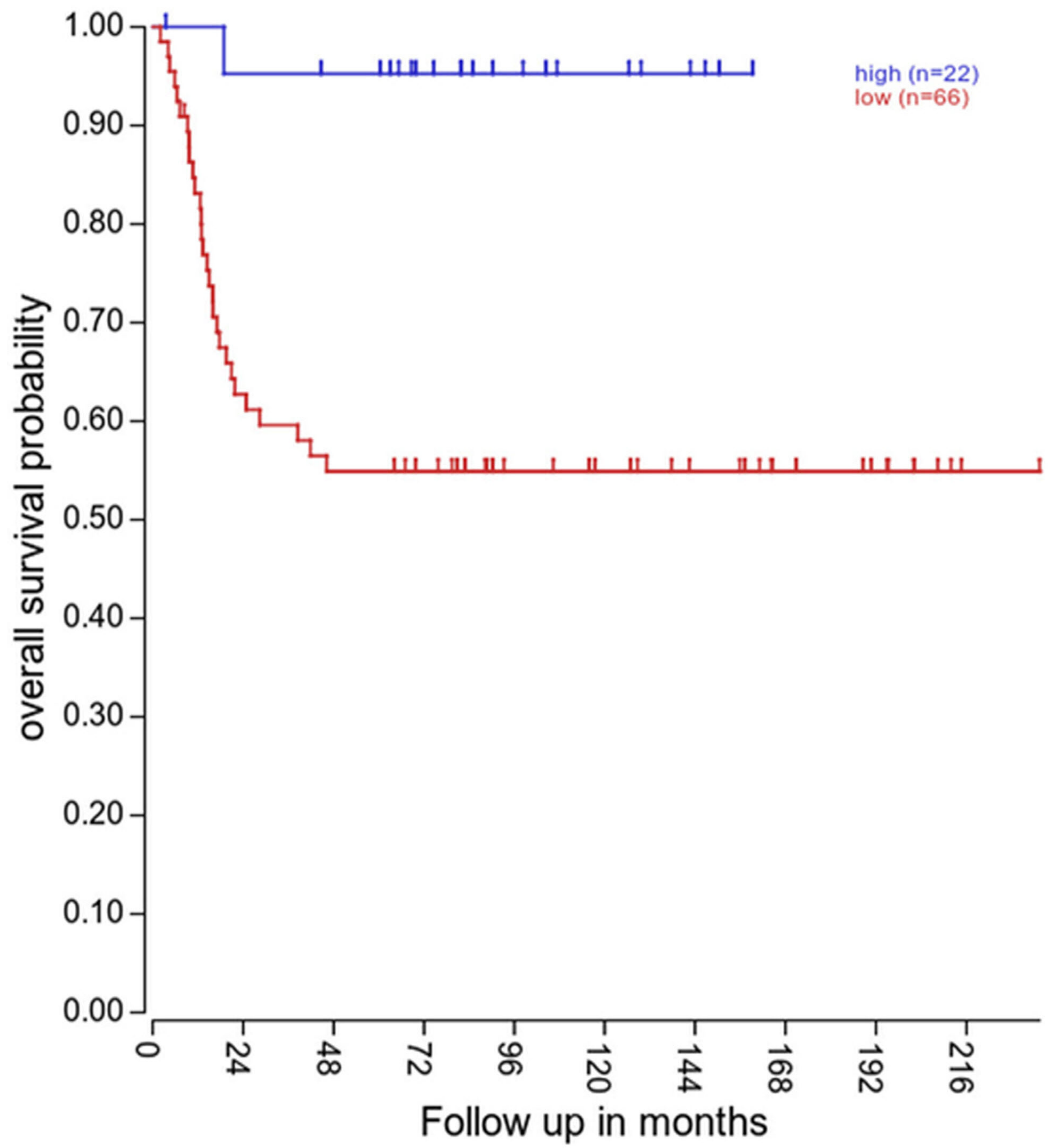

Figure 7

The potential relationship between SR expression and the prognosis of neuroblastoma patients.

Utilization of R2 program as described in the materials and methods was used to predict the relationship 
between SR expression and the prognosis of neuroblastoma patients. High level of SR expression $(n=22)$ was associated with good prognosis in neuroblastoma patients whereas low level of SR expression $(n=66)$ with bad prognosis in neuroblastoma patients. Survival rates were estimated by the Kaplan-Meier method,and the log-rank test was used to assess survival difference. ${ }^{\star \star} \mathrm{p}=0.0016$.

\section{Supplementary Files}

This is a list of supplementary files associated with this preprint. Click to download.

- Supplementalmaterials.docx 